\title{
Evaluation of the use of health care services for non-communicable disease and prevention by children and adolescents in south Italy
}

Flora Ascione, Diana Cascone, Francesco Napolitano and Gabriella Di Giuseppe*

\begin{abstract}
Background: The objectives of this investigation are to evaluate the use of health care services for noncommunicable disease and prevention by children and adolescents and to identify the factors linked to the use of health care services.

Methods: This cross-sectional survey was conducted between December 2014 and January 2015 among 1198 parents of students aged between 5 and 18 years attending 12 selected schools in the geographic area of Salerno and Naples, Italy, using a self-administered questionnarie.

Results: $68.2 \%$ of parents stated that had visited their general practitioner (GP) or family pediatrician (FP) with their child in the last year. $66.2 \%$ of children had had at least one visit to a specialist and more than half (54.8\%) had had preventive care visits in the last year. The use of preventive care visits within last year was significantly higher amongst female, among those who had visited their GP or FP and among those who had a parent with a college degree or higher. The proportion of emergency department visits and hospital admissions reported were 12.8\% and $4.7 \%$ respectively.

Conclusion: This results highlights the need of educational interventions for parents and adolescents in order to increase the utilization of preventive health services.
\end{abstract}

Keywords: Children, Cross-sectional study, Health care services use, Italy, Multivariate regression analysis

\section{Background}

Noncommunicable diseases (NCDs) cause millions of deaths each year and are responsible for over two thirds of all deaths worldwide. For this reason the Global action plan for the prevention and control of NCDs 2013-2020 has set the target of reducing by $25 \%$ the relative risk of premature mortality from these diseases by 2025 [1].

It is well known that NCDs in adulthood begin in the younger ages, and the main causes of illness and death in the population can be considered largely preventable through accessible preventative actions and changes in the lifestyles of children and adolescents [2-5].

\footnotetext{
* Correspondence: gabriella.digiuseppe@unicampania.it Department of Experimental Medicine, University of Campania Luigi Vanvitelli, Via Luciano Armanni, 5, 80138 Naples, Italy
}

Childhood is a time of rapid growth and change and since children have more visits in their early years, even if a child is healthy, the visits in this period are a good time to focus on the child's wellbeing and on prevention of diseases [6]. Indeed, the prevention of health problems helps keep a healthy child enabling them to become a healthy adult.

To improve and preserve the quality of health for children and adolescents, it is essential to have an ordinary and appropriate utilization of the health care services, which provide correct treatment and health promotion. These services include parental health education, routine ceck-ups, immunizations and preventive care visits. The use of the health care services may be affected by many factors including structural and organizational characteristics of services [7-11]; in Italy, in particular, a country 
with a system of universal health coverage, the use of the health care services are guaranteed and provided free of charge throught the family pediatricians (FP) or general practitioners (GP). GPs and FPs represents the gatekeepers in the utilization of the all services and benefits of the Italian National Health Service [12].

In published literature, several studies have investigated the use and the associated factors to health care services in children and young adults [7, 13-22] while there are few investigations regarding the utilization of preventive health services [23-26] and no research has been conducted in Italy on this issue.Therefore, it seemed interesting to evaluate the use of the health care services in a sample of children and adolescents for the treatment and prevention of their diseases and to identify the factors linked to these outcomes of interest.

\section{Methods}

This cross-sectional survey was conducted between December 2014 and January 2015 among 1198 parents of students aged between 5 and 18 years attending 12 selected schools in the geographical areas of Salerno and Naples, Italy. The survey design included a two-stage cluster sampling procedure. Specifically, in the frist stage, from the list of public schools of the geographical areas of Salerno and Naples, three primary and nine secondary schools were randomly selected. In the second stage, from each selected school the students were selected through a simple random sampling.

The sample size was determined based on the assumptions that $78 \%$ of children and adolescents had had a health care services use as in accordance with published literature $[15,18]$, a confidence interval of $95 \%$, a margin of error of $5 \%$, an expected response rate of $50 \%$ and a design effect of 2 for a total number of 1196 participants. Considering the total number of the sample size, 12 schools were selected because it was thought to sample circa 100 participants from each school.

Before starting the survey to the directors of each school were sent a letter requesting their cooperation in the survey and in which the objectives of the study and the methods to collect the information were specified. After having obtained approval, the students were given a sealed envelope to take home that contained a cover letter, an informed consent form, a questionnaire and a pre-addressed envelope to return the completed questionnaire to the organizers of the survey. The letter included a full description of the study and its importance and explained that the information would be collected respecting the parents' privacy and anonymity. It invited only one of the parents to provide the consent to participate and to complete the questionnaire. No payments or gifts were given to the respondents.
The study protocol and the questionnaire were approved by the Ethical Committee of the University of Campania Luigi Vanvitelli. Written informed consent was obtained from each parent.

The questionnaire was composed of three sections: (1) socio-demographical characteristics of the parents (gender, age, marital status, education level, employment status, number and age of children, number of cohabiting family members, partner's employment status, socioeconomic status, having family member's occupation related to health care). The socio-economic status was evalueted based on the household employment status; (2) socio-demographical and clinical characteristics of the children (gender, age, school, chronic conditions and health status in the last year, the parent's perception of the children health status); (3) use of health care services in the previous 12 months (reasons and number of GP/FP visits, type, reasons and number of specialist visits, type and number of preventive care visits, reasons and number of visits to the emergency department (ED), reasons and number of hospital admissions). The preventive care visits have been defined as a consultation or periodic physical examination to identify potential health problems in healthy people. The self-administered questionnaire included closed and open-ended types of questions and 5point Likert scale responses (see Additional file 1).

Before starting the survey, a pilot study was carried out on a sample of 25 parents, which was not included in the final sample, to test the understandability and clarity of the questionnarie questions.

\section{Statistical analysis}

Following a descriptive analysis of the data, the inferential analysis was conducted according to a double stage strategy. In the first stage, four multivariate logistic regression full models were built to evaluate the effect of each independent variable on the following outcomes of interest: utilization of the GP or pediatrician in the last year (Model 1), at least one specialist visit in the last year (Model 2), at least one preventive care visit in the last year (Model 3) and at least one emergency department visit in the last year (Model 4). In this stage, the selection of variables included in saturated models was done considering previous investigation in published literature $[14,15,18,20]$, while other variables were chosen because they were considered as interesting predictors of the outcomes. In the second stage, the variables included in the final models were determined using a backwards selection procedure and the significance level for variables for removal from the model was set at 0.4. The Hosmer and Lemeshow test was used to assess the goodness-of-fit of the final models. The following variables were included in all Models: gender of parents (male $=0$; female $=1$ ), age of parent (continous, in 
years), gender of children (male $=0$; female $=1$ ), age of children (continous, in years), educational level of at least one parent (others $=0$; college degree or higher $=1$ ), number of cohabiting (continous), at least one parent who is a health care professional (no $=0$; yes $=1)$, socioeconomic status (three categories: low $=1$; intermediate $=2$; high $=3$ ), days lost from school due to illness (no $=0 ;$ yes $=1$ ), chronic conditions of children $(0=$ none; $1=\geq 1)$, health problem in the last year (no $=0$; yes $=1)$, parent's perception of health problem of child (others $=0$; serious $=1$ ), at least one hospital admission in the last year $($ no $=0$; yes $=1$ ). The variable at least one specilist visit in the last year $($ no $=0$; yes $=1$ ) was included in Model 1 and in Model 4. The variable emergency department visits in the last year $($ no $=0$; yes $=1$ ) was included in Model 1 , in Model 2 and in Model 3. The variable at least one preventive care visit in the last year (no $=0$; yes $=1$ ) was included in Model 1 and Model 4. Finally,the variable utilization of the GP or FP in the last year (no $=0$; yes $=1$ ) was included in Model 2, in Model 3 and in Model 4 (see Additional file 2).

The results of the multivariate regression models have been expressed as odds ratios (ORs) and 95\% confidence intervals (CIs) with a statistically significant level of $p$ value $\leq 0.05$. Statistical analyses were performed using Stata version 10.1 software [27].

\section{Results}

\section{Participants' characteristics}

In total, 1198 questionnaires were distributed and 891 parents agreed to participate in the survey with a response rate of $74.4 \%$. 231 participants were parents of children selected from the three primary schools and 660 were parents of the students attending the nine secondary schools. The main characteristics of the children and parents are described in Table 1. More than twothirds of parents were female (77.8\%) and married $(87.8 \%)$, the average age was 43.4 years. More than half of the sample had at least one child (61.2\%) and approximately half of the sample had completed the high school education (49.3\%). Regarding the children's characteristics, only $9.6 \%$ had at least one parent who was a health care professional. The majority were female (59.7\%), the average age was 12.6 years, approximately one in five had at least one chronic condition and $43.7 \%$ had had days absent from school due to health problems in the last year. Moreover, almost all parents (93.6\%) considered the health status of their children to be at least good.

\section{Utilization of health care services in the previous 12 months}

The proportion of utilization of at least one health care service (FP, GP, specialist, ED, hospital admission) by
Table 1 Main characteristics of the children and parents

\begin{tabular}{|c|c|c|}
\hline \multirow{3}{*}{$\overline{P a r e n t s}$} & \multicolumn{2}{|l|}{ Total } \\
\hline & \multicolumn{2}{|c|}{$(n=891)$} \\
\hline & $\mathrm{N}$ & $\%$ \\
\hline \multicolumn{3}{|l|}{ Gender } \\
\hline Male & 198 & 22.2 \\
\hline Female & 693 & 77.8 \\
\hline Age (years) & \multicolumn{2}{|c|}{$43.4 \pm 6.4(21-71)^{\mathrm{a}}$} \\
\hline \multicolumn{3}{|l|}{ Marital status } \\
\hline Married & 783 & 87.8 \\
\hline Other & 108 & 12.2 \\
\hline \multicolumn{3}{|l|}{ Educational level } \\
\hline Primary school or less & 20 & 2.3 \\
\hline Middle school & 166 & 18.6 \\
\hline High school & 439 & 49.3 \\
\hline Baccalaureate/graduate degree & 266 & 29.8 \\
\hline \multicolumn{3}{|c|}{ At least one parent who is a health care professional } \\
\hline No & 805 & 90.4 \\
\hline Yes & 86 & 9.6 \\
\hline \multicolumn{3}{|l|}{ Number of children } \\
\hline 1 & 107 & 12 \\
\hline 2 & 545 & 61.2 \\
\hline$>2$ & 239 & 26.8 \\
\hline Number of cohabiting & \multicolumn{2}{|c|}{$3.3 \pm 1.1(1-10)^{a}$} \\
\hline \multicolumn{3}{|l|}{ Children } \\
\hline \multicolumn{3}{|l|}{ Gender } \\
\hline Male & 359 & 40.3 \\
\hline Female & 532 & 59.7 \\
\hline Age (years) & \multicolumn{2}{|c|}{$12.6 \pm 3.5(5-18)^{\mathrm{a}}$} \\
\hline $5-10$ & 231 & 25.9 \\
\hline $11-14$ & 353 & 39.6 \\
\hline $15-18$ & 307 & 34.5 \\
\hline \multicolumn{3}{|l|}{ Chronic conditions } \\
\hline None & 744 & 83.5 \\
\hline At least one & 147 & 16.5 \\
\hline \multicolumn{3}{|l|}{ Health problems in the last year } \\
\hline No & 602 & 67.6 \\
\hline Yes & 289 & 32.4 \\
\hline \multicolumn{3}{|l|}{ Parent's perception of health problem } \\
\hline Very slight & 301 & 33.8 \\
\hline Slight & 198 & 22.2 \\
\hline Moderate & 352 & 39.5 \\
\hline Serious & 40 & 4.5 \\
\hline \multicolumn{3}{|c|}{ Having day lost from school due to health problems } \\
\hline No & 502 & 56.3 \\
\hline Yes & 389 & 43.7 \\
\hline
\end{tabular}

${ }^{a}$ Mean \pm standard deviation (range)

Number for each item may not add up to total number of study population due to missing value 
children in the previous 12 months was $91.6 \%$ and is detailed in Table 2.

$32.4 \%$ of respondents reported that their child had had a health problem in the last year and $68.2 \%$ reported at least one visit to the GP or FP in the previous 12 months. Among these parents, $54.7 \%$ were going to their GP because of confidence in their professional abilities and $32.2 \%$ for the ease utilization. Among the parents who had not gone preliminarily to their GP or FP, the main reasons were the long waiting time for the utilization (42.2\%) and the greater chance of having a more appropriate diagnosis from a specialized ambulatory center $(32.7 \%)$. The results of the multiple logistic regression analysis revealed that the utilization of the GP or FP in the last year was significantly higher amongst children who had experienced a health problem in the last year $(\mathrm{OR}=1.7$; CI 95\% = 1.17-2.48), amongst those whose parents perceived their health problem as serious $(\mathrm{OR}=4.39$; CI 95\% = 1.29-14.92), among children who had been absent from school due to health problem $(\mathrm{OR}=1.67$; CI 95\% = 1.19-2.33 $)$ and amongst those who had had at least one specialist $(\mathrm{OR}=1.47$; $\mathrm{CI}$ $95 \%=1.01-2.14)$ and preventive care visit in the last year $(\mathrm{OR}=2.35 ; \mathrm{CI} 95 \%=1.64-3.38)$. However, the utilization of the GP or FP was significantly lower in younger children $(\mathrm{OR}=0.91 ; \mathrm{CI} 95 \%=0.87-0.0 .96)$ and amongst those who had at least one parent who was a health care professional $(\mathrm{OR}=0.35$; CI 95\% $=0.21-0.6)$ (Table 3).
Regarding the utilization of a specialist, $66.2 \%$ of children had had at least one visit to a specialist in the last year with a mean of 2.7 and more than half (60.6\%) had had at least one dental visit with a mean of 4.3. The medical specialist visits more frequently reported (excluding dental visits) were visits to ophthalmologist (68.6\%), dermatology (30.4\%), orthopedic (26.8\%) and otolaryngology $(21.4 \%)$ specialists. The utilization of a specialist (excluding dental visits) was more likely among female children $(\mathrm{OR}=1.86 ; \mathrm{CI} 95 \%=1.38-2.51)$, and amongst those who had had at least one visit to the GP or $\mathrm{FP}(\mathrm{OR}=2.36$; CI 95\% = 1.72-3.24) and emergency department in the last year $(\mathrm{OR}=2.06$; CI 95\% = 1.24-3.43) (Table 3).

More than half of the children (54.8\%) had had preventive care visits in the last year. Whereas only $8.1 \%$ of children had had preventive care dental visits. The more frequent preventive care visits for children reported by parents (excluding dental visits) were visits to ophthalmologist (69.1\%), orthopedic (15.2\%), otolaryngology (13.1\%) and dermatology (10.5\%) specialists. The model built to evaluate the variables associated with the use of preventive health care services (excluding preventive dental visits) in the last year showed that this use was significantly higher amongst female children $(\mathrm{OR}=1.72$; CI $95 \%=1.29-2.31)$, among those who had GP or FP utilization $(\mathrm{OR}=2.85$; CI 95\% $=2.09-3.88)$, amongst younger children $(\mathrm{OR}=0.95 ; \mathrm{CI} 95 \%=0.91-0.99)$, amongst children whose parent was older in age

Table 2 Utilization of health care services of overall sample according to the different age groups

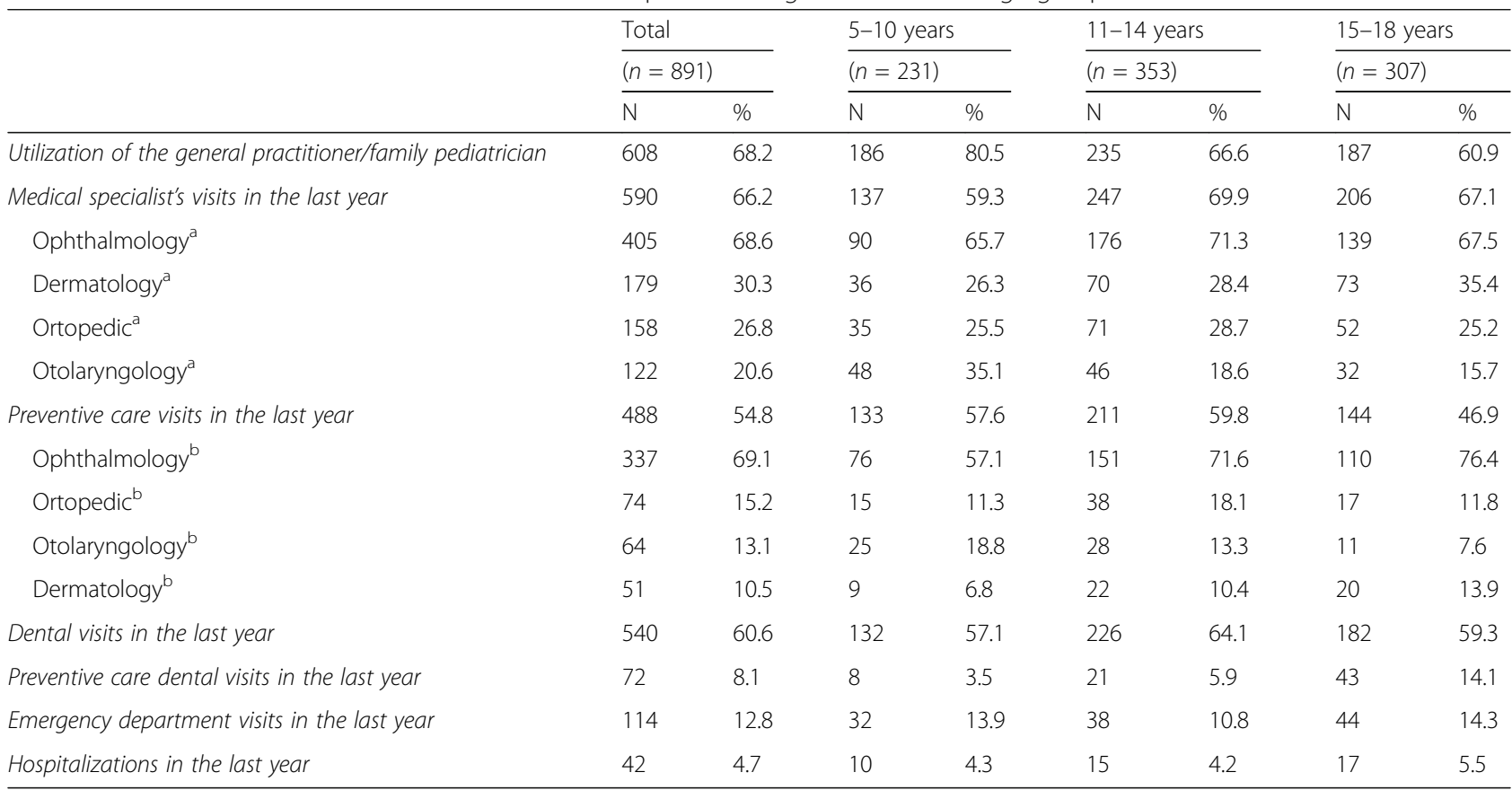

${ }^{a}$ Only for children who have at last one specialist visit in the last year $(n=590)$

${ }^{\mathrm{b}}$ Only for children who have at last one preventive care visit in the last year $(n=488)$ 
Table 3 Results of multivariate regression analysis to explore the characteristics associated with the use of the health care services

\begin{tabular}{|c|c|c|c|c|}
\hline Variable & OR & SE & $95 \% \mathrm{Cl}$ & $p$ value \\
\hline \multicolumn{5}{|l|}{ Model 1. General practitioners or family pediatricians utilization in the last year } \\
\hline \multicolumn{5}{|l|}{ Log likelihood $=-477.2 x^{2}=145.66(12 d f), p<0.0001$} \\
\hline At least one parent who is a health care professional & 0.35 & 0.09 & $0.21-0.6$ & $<0.001$ \\
\hline At least one preventive care visit in the last year & 2.35 & 0.43 & $1.64-3.38$ & $<0.001$ \\
\hline Age of children & 0.91 & 0.02 & $0.87-0.96$ & 0.001 \\
\hline Days lost from school due to illness & 1.67 & 0.28 & $1.19-2.33$ & 0.003 \\
\hline Health problems in the last year & 1.7 & 0.33 & $1.17-2.48$ & 0.005 \\
\hline Perception of health problem by the parent & 4.39 & 2.74 & $1.29-14.92$ & 0.018 \\
\hline At least one medical specialist's visits in the last year & 1.47 & 0.28 & $1.01-2.14$ & 0.041 \\
\hline Educational level & 1.37 & 0.25 & $0.95-1.97$ & 0.09 \\
\hline At least one hospital admission in the last year & 2.35 & 1.24 & $0.83-6.64$ & 0.106 \\
\hline Gender of children & 0.98 & 0.01 & $0.95-1.01$ & 0.187 \\
\hline Chronic conditions & 1.39 & 0.32 & $0.88-2.19$ & 0.158 \\
\hline Emergency department visits in the last year & 1.31 & 0.35 & $0.77-2.21$ & 0.312 \\
\hline \multicolumn{5}{|l|}{ Model 2. Specialist utilization in the last year } \\
\hline \multicolumn{5}{|l|}{ Log likelihood $=-528.5 x^{2}=68(10 d f), p<0.0001$} \\
\hline At least one visit to general practitioners or family pediatricians in the last year & 2.36 & 0.38 & $1.72-3.24$ & $<0.001$ \\
\hline Gender of children & 1.86 & 0.28 & $1.38-2.51$ & $<0.001$ \\
\hline Emergency department visits in the last year & 2.06 & 0.53 & $1.24-3.43$ & 0.005 \\
\hline Age of children & 1.05 & 0.02 & $0.99-1.1$ & 0.054 \\
\hline Age of parent & 1.02 & 0.01 & $0.99-1.05$ & 0.134 \\
\hline Health problems in the last year & 1.28 & 0.21 & $0.93-1.78$ & 0.138 \\
\hline \multicolumn{5}{|l|}{ Number of children } \\
\hline 1 & $1^{\mathrm{a}}$ & & & \\
\hline$>2$ & 0.84 & 0.14 & $0.61-1.17$ & 0.301 \\
\hline At least one hospital admission in the last year & 0.69 & 0.26 & $0.33-1.46$ & 0.343 \\
\hline Educational level & 1.16 & 0.19 & $0.84-1.61$ & 0.356 \\
\hline Gender of parent & 1.18 & 0.22 & $0.82-1.69$ & 0.382 \\
\hline \multicolumn{5}{|l|}{ Model 3. Preventive care visits in the last year } \\
\hline \multicolumn{5}{|l|}{ Log likelihood $=-564.68 x^{2}=85.75(11 d f), p<0.0001$} \\
\hline At least one visit to general practitioners or family pediatricians in the last year & 2.85 & 0.45 & $2.09-3.88$ & $<0.001$ \\
\hline Gender of children & 1.72 & 0.25 & $1.29-2.31$ & $<0.001$ \\
\hline Educational level & 1.5 & 0.27 & $1.06-2.13$ & 0.023 \\
\hline Age of children & 0.95 & 0.02 & $0.91-0.99$ & 0.029 \\
\hline Age of parent & 1.03 & 0.01 & $1.01-1.06$ & 0.033 \\
\hline Number of cohabiting & 1.13 & 0.08 & $0.98-1.3$ & 0.086 \\
\hline Chronic conditions & 1.3 & 0.26 & $0.88-1.92$ & 0.181 \\
\hline \multicolumn{5}{|l|}{ Socio-economic status } \\
\hline low & $1^{a}$ & & & \\
\hline medium & 1.2 & 0.2 & $0.87-1.66$ & 0.260 \\
\hline Gender of parent & 1.22 & 0.22 & $0.86-1.74$ & 0.266 \\
\hline \multicolumn{5}{|l|}{ Number of children } \\
\hline 1 & $1^{a}$ & & & \\
\hline 2 & 1.15 & 0.17 & $0.85-1.55$ & 0.354 \\
\hline
\end{tabular}


Table 3 Results of multivariate regression analysis to explore the characteristics associated with the use of the health care services (Continued)

\begin{tabular}{|c|c|c|c|c|}
\hline Health problems in the last year & 0.87 & 0.14 & $0.64-1.19$ & 0.394 \\
\hline \multicolumn{5}{|l|}{ Model 4. Emergency department visits in the last year } \\
\hline \multicolumn{5}{|l|}{ Log likelihood $=-564.68 x^{2}=85.75(11 \mathrm{df}), p<0.0001$} \\
\hline At least one hospital admission in the last year & 8.79 & 3.27 & $4.24-18.22$ & $<0.001$ \\
\hline Educational level & 0.4 & 0.11 & $0.23-0.69$ & 0.001 \\
\hline At least one medical specialist's visits in the last year & 2.45 & 0.69 & $1.41-2.26$ & 0.001 \\
\hline Chronic conditions & 2.09 & 0.53 & $1.27-3.46$ & 0.004 \\
\hline Health problems in the last year & 1.71 & 0.39 & $1.09-2.66$ & 0.018 \\
\hline Age of parent & 0.97 & 0.01 & $0.94-1.01$ & 0.096 \\
\hline \multicolumn{5}{|l|}{ Socio-economic status } \\
\hline low & $1^{a}$ & & & \\
\hline medium & 0.71 & 0.17 & $0.45-1.13$ & 0.151 \\
\hline Gender of children & 0.73 & 0.16 & $0.47-1.12$ & 0.156 \\
\hline Perception of health problem by the parent & 0.47 & 0.26 & $0.16-1.39$ & 0.175 \\
\hline \multicolumn{5}{|l|}{ Number of children } \\
\hline 1 & $1^{\mathrm{a}}$ & & & \\
\hline 2 & 0.77 & 0.18 & $0.49-1.21$ & 0.258 \\
\hline Number of cohabiting & 1.11 & 0.1 & $0.91-1.35$ & 0.288 \\
\hline At least one preventive care visit in the last year & 0.78 & 0.19 & $0.49-1.25$ & 0.31 \\
\hline
\end{tabular}

${ }^{\mathrm{a}}$ Reference category

$(\mathrm{OR}=1.03 ; \mathrm{CI} 95 \%=1.01-1.06)$ and amongst children whose parent had a college degree or higher $(\mathrm{OR}=1.5$; CI 95\% = 1.06-2.13) (Table 3).

The proportion of emergency department visits and hospital admissions of children reported were $12.8 \%$ and $4.7 \%$ respectively. The utilization of the emergency department was significantly more likely amongst children who had experienced a health problem in the last year $(\mathrm{OR}=1.71 ; \mathrm{CI} 95 \%=1.09-2.66)$, amongst those who had chronic conditions $(\mathrm{OR}=2.09$; $\mathrm{CI} 95 \%=1.27-$ 3.46), amongst those who had at least one specialist visit in the last year $(\mathrm{OR}=2.45$; CI $95 \%=1.41-2.26)$ and amongst the children who had had hospital admissions in the last year $(\mathrm{OR}=8.79$; CI 95\% = 4.24-18.22). Moreover, the utilization of the emergency department was lower amongst children whose parent had a college degree or higher $(\mathrm{OR}=0.4 ; \mathrm{CI} 95 \%=0.23-0.69)$ (Table 3$)$.

\section{Discussion}

To our knowledge, this survey is the first study carried out in Italy that evaluated the use of health care services, and the relative predictors, by children and adolescents regarding both the treatment and the prevention of diseases. The findings of this survey are difficult to compare with those of other studies conducted worldwide due the different characteristics of the populations sampled, methodologies, study period and the differences of the health care services in these countries.
In this study almost all children (91.6\%) had had at least one utilization of health care services in the previous year. This result is in accordance with a value (92.5\%) founded in Spain [18] but is higher than that found in a crosssectional survey conducted among a large sample of children and adolescents from 11 European countries (65.4\%) [15] and in a study among children aged 0 to 17 years in the USA (72\%) [19]. Of more interest is that only twothirds of the sample had had at least one visit to their GP or FP in the last year. This value is very low considering that Italy is a country with a system of universal health coverage and the utilization of the FP or GP is provided free of charge to all members of public. Moreover, among the parents who had not gone preliminarily to their GP or $\mathrm{FP}$, the main reasons were the long waiting time for the utilization and the greater chance of having a more appropriate diagnosis from a specialist. These results point to the need for other sudies to investigate more thoroughly the non-medical mechanism of the health services use in order to provide important information to policy makers. However, the value of the utilization of the GP or FP in our survey is in accordance with the values found in a study conducted in Germany (68.3\%) among younger adolescents [28] and in a survey conducted in Canada among adolescent and young adults. The latter found $67.1 \%$ of adolescents between 12 to 14 year olds and $69.8 \%$ between 15 to 19 year olds had used their family pediatrician in the last 12 months [29]. 
A key objective of this study was to investigate the frequency of preventive care visits among children and adolescents. In our sample, $54.2 \%$ of children had had at least one preventive care visit in the last year. These values are low and alarming since childhood and adolescence are key periods for the prevention and early treatment of health issues. Also, several institutions have developed guidelines and recommendations for the prevention of diseases and the protection of the health of infants, children and adolescents through the improvement of the quality of health care services, the continuity of care and access to regular preventive visits [30-32]. In other studies the proportions of preventive care visits for children and adolescents were higher than those observed in our study. In particular, the rates of preventive medical care visits were $88.2 \%, 68.9 \%$ and $69 \%$ respectively in early childhood, middle childhood and adolescence [23], 88.3\% among children aged 1 to 17 years [17], 72\% among children of married parents [14] and between 43 and 81.2\% among a sample of adolescents in a study which compared three surveys [26]. Conversely, the proportion of children who had had at least one preventive care visit was lower in previous studies conducted in the USA [19, 20, 24].

Very low in this survey was the proportion of children who had had preventive care dental visits in the previous 12 months. Indeed, only $8.1 \%$ of children had at least one preventive dental visit. This worrying result can be explained by the fact that in Italy free public utilization of dental care is very difficult and that there are few public health facilities that provide dental services. Indeed, the value that has been observed is much lower than those reported in other studies, since a range from $38.8 \%$ to $82.6 \%$ of children had preventive dental care visit in the US [14, 17, 33, 34], 35.4\% in Jordan [35], $35.3 \%$ of 12 year-olds and $20.2 \%$ of 18 year-olds children in China [36] and $12.5 \%$ in India [37].

In our study only $12.8 \%$ of the children had had emergency department visits in the last year. This observed value is lower than those reported in other studies, such as in two studies conducted in the US where the frequency of reported ED visits was respectively $29 \%$ and $19 \%[20,21]$. In a study conducted in the UK, one in three children had at least one utilization of the ED [22] and our observed value is identical to the levels of $12.8 \%$ of ED use among children reported in the USA [13] and to $12 \%$ reported in an already cited study [19].

Four multivariate regression models have been developed to evaluate the association of the characteristics of parents and children with the use of different health care services. Several characteristics including age and sex of children, educational level of parents, health status of children and the utilization of health care services were significantly associated with the different outcomes of interest. In particular, the preventive care visit was significantly more likely among children who had parents with a higher educational level. This finding has been found in previous studies [14]. Instead, in this survey a higher parental education level was inversely associated with the use of the emergency department. More interestingly in this study is that the use of the ED was strongly associated to chronic conditions and to the use of the other health care facilities such as specialist visits and hospital admission in the last year. These results are probably due to the fact that the children with chronic disorders are more in need of the utilization of the health care services.

This study has some limitations that should be considered in evaluating the results. Firstly, this study is a crosssectional survey where the temporal direction of the association between the outcomes and the independent variables cannot be determined. Secondly, since we had asked parents to indicate the use of the health services for their children in the last 12 months, a recall bias may have occurred that could lead to underestimate or overestimate the use of health care services. The recall bias may affect the reliability of the data in particular for the responses regarding the reasons of consultation and the numbers of previous visits by GP or FP and the utilization of health care services for children and adolescents with chronic conditions. Finally, we have considered the use of health services in an area of the Campania Region which may be different from that of analogous samples in other Italian regions, in particular regarding the utilization of the preventive services. Therefore, although we cannot exclude that our results pertain only to our area, it is reasonable to assume that our sample may be analogous to that of other regions of southern Italy. To get a clearer framework regarding the use of health services by children and adolescents in Italy, we strongly recommend the replication of the study in the regions of the north of the country.

\section{Conclusion}

In conclusion, this study provides relevant information on the use of health services by children and adolescents in Southern Italy. Relevants findings were the low value of the preventive visits rates and the higher educational level of parents as one of main determinants of using the preventive health services while no association was observed between the parent's socio-economic status and preventive care utilization. These results highlight the need of educational interventions for parents and adolescents in order to increase the utilization of preventive health services. Moreover, parents' responses have also revealed some non-medical reasons for which they chose to use the services and, since this study did not evaluate the access to services, future studies should addressed this topic to provide to policy makers and physicians information to make health care services more accessible, usable and efficient. 


\section{Additional files}

Additional file 1: Questionnaire: Self-administered questionnaire used for the survey. (DOCX $19 \mathrm{~kb})$

Additional file 2: Regression Modeling Strategy: Modeling Strategy used to build the multivariate regression final models. (DOCX $36 \mathrm{~kb}$ )

\section{Abbreviations}

Cl: Confidence interval; ED: Emergency department; FP: Family pediatrician; GP: General practitioner; NCDs: Noncommunicable diseases; OR: Odds ratios.

\section{Acknowledgements}

The research team would like to thank the directors and the teachers of the selected schools for their assistance during the data collection and parents who contributed their precious time.

\section{Funding}

None.

\section{Availability of data and materials}

All data generated or analysed during this study is included in this published article. The datasets used and analysed during the current study are available from the corresponding author on reasonable request.

\section{Authors' contributions}

FA and DC participated in the design of the study and were responsible for the data collection; FN performed the statistical analysis, contributed to the interpretation and wrote the paper; GDG the principal investigator, designed the study, was responsible for the data collection, statistical analysis and interpretation, and wrote the paper. All authors read and approved the final manuscript.

\section{Ethics approval and consent to participate}

The study protocol and the questionnaire were approved by the Ethical Committee of the University of Campania Luigi Vanvitelli. Written informed consent was obtained from each parent.

\section{Consent for publication}

Not applicable.

\section{Competing interests}

The authors declare that they have no competing interests.

\section{Publisher's Note}

Springer Nature remains neutral with regard to jurisdictional claims in published maps and institutional affiliations.

Received: 26 December 2016 Accepted: 1 August 2017 Published online: 04 August 2017

\section{References}

1. World Health Organization. Global Action Plan for the Prevention and Control of NCDs 2013-2020. http://www.who.int/nmh/events/ncd_action_ plan/en/. Accessed Aug 242016.

2. Must A, Jacques PF, Dallal GE, Bajema CJ, Dietz WH. Long-term morbidity and mortality of overweight adolescents: a follow-up of the Harvard growth study of 1922 to 1935. N Engl J Med. 1992;327:1350-5.

3. Reilly J, Methven E, McDowell Z, Hacking B, Alexander D, Stewart L, et al, Health consequences of obesity. Arch Dis Child. 2003;88:748-52.

4. Wang Y, Lobstein T. Worldwide trends in childhood overweight and obesity. Int J Pediatr Obes. 2006;1:11-25.

5. Ho TF. Cardiovascular risks associated with obesity in children and adolescents. Ann Acad Med Singap. 2009:38:48-9.

6. Committee On Practice And Ambulatory Medicine, Bright Futures Periodicity Schedule Workgroup. 2017 recommendations for preventive pediatric health care. Pediatrics. 2017;pii:e20170254

7. Saxena S, Eliahoo J, Majeed A. Socioeconomic and ethnic group differences in self reported health status and use of health services by children and young people in England: cross sectional study. BMJ. 2002;325:520-5. Erratum in BMJ. 2003:327:325

8. Newacheck PW, Hung YY, Park MJ, Brindis CD, Irwin CE Jr. Disparities in adolescent health and health care: does socioeconomic status matter? Health Serv Res. 2003;38:1235-52.

9. Skinner AC, Mayer ML. Effects of insurance status on children's access to specialty care: a systematic review of the literature. BMC Health Serv Res. 2007;7:19.

10. van Doorslaer E, Masseria C, Koolman X. OECD health equity research group. Inequalities in access to medical care by income in developed countries. CMAJ. 2007:174(2):177-83.

11. Chaupain-Guillot S, Guillot O. Health system characteristics and unmet care needs in Europe: an analysis based on EU-SILC data. Eur J Health Econ. 2015;16:781-96

12. Ministero della salute. Servizi al cittadino ed al paziente. http://www.salute. gov.it/portale/salute/p1_4.jsp?lingua=italiano\&area=Servizi_al_cittadino_e_ al paziente. Accessed August 242016.

13. Selden TM, Hudson JL. Access to care and utilization among children: estimating the effects of public and private coverage. Med Care. 2006:44:119-26.

14. Gorman BK, Braverman J. Family structure differences in health care utilization among U.S. children. Soc Sci Med. 2008;67:1766-75.

15. Berra S, Tebé C, Erhart M, Ravens-Sieberer U, Auquier P, Detmar $S$, et al. Correlates of use of health care services by children and adolescents from 11 European countries. Med Care. 2009;47:161-7.

16. DeVoe JE, Tillotson CJ, Wallace LS, Angier H, Carlson MJ, Gold R. Parent and child usual source of care and children's receipt of health care services. Ann Fam Med. 2011;9:504-13.

17. Strickland BB, Jones JR, Ghandour RM, Kogan MD, Newacheck PW. The medical home: health care access and impact for children and youth in the United States. Pediatrics. 2011:127:604-11.

18. Palacio-Vieira JA, Villalonga-Olives E, Valderas JM, Herdman M, Alonso J, Rajmil L. Predictors of the use of healthcare services in children and adolescents in Spain. Int J Public Health. 2013;58:207-15.

19. Romaire MA, Bell JF, Grossman DC. Health care use and expenditures associated with access to the medical home for children and youth. Med Care. 2012:50:262-9.

20. Romaire MA, Bell JF, Grossman DC. Medical home access and health care use and expenditures among children with special health care needs. Arch Pediatr Adolesc Med. 2012;166:323-30.

21. Zickafoose JS, DeCamp LR, Prosser LA. Association between enhanced access services in pediatric primary care and utilization of emergency departments: a national parent survey. J Pediatr. 2013;163:1389-95.

22. Cecil E, Bottle A, Cowling TE, Majeed A, Wolfe I, Saxena S. Primary care access, emergency department visits, and unplanned short hospitalizations in the UK. Pediatrics. 2016:137:e20151492.

23. Van Cleave J, Davis MM. Preventive care utilization among children with and without special health care needs: associations with unmet need. Ambul Pediatr. 2008;8:305-11.

24. Irwin CE Jr, Adams SH, Park MJ, Newacheck PW. Preventive care for adolescents: few get visits and fewer get services. Pediatrics. 2009;123:e565-72.

25. Wieske RC, Nijnuis MG, Carmiggelt BC, Wagenaar-Fischer MM, BoereBoonekamp MM. Preventive youth health care in 11 European countries: an exploratory analysis. Int J Public Health. 2012:57:637-41.

26. Adams SH, Park MJ, Irwin CE Jr. Adolescent and young adult preventive care: comparing National Survey Rates. Am J Prev Med. 2015:49:238-47.

27. StataCorp. Stata Statistical Software: Release 10. College Station: StataCorp LP: 2007

28. Schmidt S, Thyen U, Herrmann-Garitz C, Bomba F, Muehlan H. The youth health care measure-satisfaction, utilization, and needs (YHC-SUN)development of a self-report version of the child health care (CHC-SUN) proxy-measure. BMC Health Serv Res. 2016;20(16):189.

29. Ryan BL, Stewart M, Campbell MK, Koval J, Thind A. Understanding adolescent and young adult use of family physician services: a crosssectional analysis of the Canadian community health survey. BMC Fam Pract. 2011;12:118

30. American Academy of Pediatrics. Bright futures quidelines for health supervision of infants, children, and adolescents. 3rd ed. Elk Grove Village: American Academy of Pediatrics; 2008.

31. World Health Organization. Early child development. http://www.who.int/ social_determinants/themes/earlychilddevelopment/en/. Accessed August 242016. 
32. Ministero della Salute. Piano Nazionale della Prevenzione 2014-2018. www. salute.gov.t//imgs/c_17_pubblicazioni_2285_allegato.pdf. Accessed August 242016.

33. Macek MD, Edelstein BL, Manski RJ. An analysis of dental visits in U.S.

children, by category of service and sociodemographic factors, 1996. Pediatr Dent. 2001;23:383-9.

34. Berdahl T, Hudson J, Simpson L, McCormick MC. Annual report on Children's health care: dental and orthodontic utilization and expenditures for children, 2010-2012. Acad Pediatr. 2016;16:314-26.

35. Al-Omiri MK, Al-Wahadni AM, Saeed KN. Oral health attitudes, knowledge, and behavior among school children in North Jordan. J Dent Educ. 2006;70: 179-87.

36. Zhu L, Petersen PE, Wang HY, Bian JY, Zhang BX. Oral health knowledge, attitudes and behaviour of children and adolescents in China. Int Dent J. 2003;53:289-98.

37. Suprabha BS, Rao A, Shenoy R, Khanal S. Utility of knowledge, attitude, and practice survey, and prevalence of dental caries among 11- to 13-year-old children in an urban community in India. Glob Health Action. 2013;6:20750.

Submit your next manuscript to BioMed Central and we will help you at every step:

- We accept pre-submission inquiries

- Our selector tool helps you to find the most relevant journal

- We provide round the clock customer support

- Convenient online submission

- Thorough peer review

- Inclusion in PubMed and all major indexing services

- Maximum visibility for your research

Submit your manuscript at www.biomedcentral.com/submit
Biomed Central 